\title{
GEOGRAFIAS DA IMIGRAÇÃO HAITIANA PARA O BRASIL
}

\section{Geographies of Haitian's immigration to Brazil}

\author{
Isis do Mar Marques Martins \\ Núcleo Interdisciplinar de Estudos Migratórios - IPPUR/UFRJ \\ isisdomar@gmail.com
}

Artigo enviado para publicação em 02/10/2017 e aceito em 22/02/2018

DOI: $10.12957 /$ tamoios.2018.30652

\begin{abstract}
Resumo: O presente artigo visa refletir sobre o recente fluxo de haitianos no Brasil e suas implicações práticas, isto é, quanto aos atravessamentos sociais e políticos imbricados no espaço e no tempo da permanência aqui. Bem como suas implicações de ordem conceitual, sobretudo à luz de conceitos contemporâneos da geografia que promovem a ideia de movimento e mobilidade. Entendendo a singularidade da imigração haitiana para o Brasil e seus reflexos, dentre elas o poder de capilaridade expressivo dos haitianos no território brasileiro, a proposta é analisar a ideia de território-rede, caracterizada pela promoção de diversas relações de poder no espaço, atraída por diversos agentes, no qual tal capilaridade aponta certamente a importância das redes múltiplas que grupos haitianos aportam em suas estratégias de permanência.
\end{abstract}

Palavras-chave: imigrantes haitianos, capilaridade, território-rede, agentes espaciais

Abstract: The work sees to reflect about the actually mobility of Haitians in Brazil and your implication, or your social and political crossings in space and time of Haitians here. Also, your implications in conceptual order, especially from the point of view of Geographic's recent concepts what movement and mobility idea are promoters. Understanding the Haitian's immigration in Brazil, their singularities and your reflects, mainly the power of Haitian's capillarity in Brazil. The proposal is to analyses the idea of territory-network, which is characterized by the promotion of power ships in the space, agencies multiply attracted by several agents, in which such capillarity certainly points out the importance of the multiple networks that Haitian groups contribute in their strategies of permanence.)

Key-words: Haitians immigrants, capillarity, territory-network, spacial agents. 


\section{INTRODUÇÃO}

Compreende-se que os imigrantes perfazem e transformam suas estratégias de mobilidade tanto a partir de sua singularidade como migrante e quanto a partir de um grupo coletivo que apresenta demandas sociais e políticas no lugar chegado. O teor e as características dessas estratégias se diversificam ora como o papel do migrante e de sua singularidade no tocante à sua mobilidade, ora enquanto parte de um grupo de um corpo coletivo que viabiliza a melhoria de sua própria condição como cidadão em um país estranho.

No caso dos haitianos no Brasil, essas estratégias, principalmente no âmbito de coletivos migrantes, têm se mostrado peculiar quanto aos grupos migrantes então conhecidos por seus fluxos para este país. A capilaridade e a maneira que se arranjam territorialmente já apontam essa peculiaridade, mas são fundamentalmente nas formas coletivas de reivindicação de direitos e no amparo coletivo que os haitianos promovem estratégias de mobilidade singulares.

Muitas dessas reivindicações são resultados de vários elementos, em especial no arranjo das estratégias de mobilidade de grupos migrantes e o percurso da política do Estado brasileiro, que acaba também por direcionar suas estratégias na mobilidade de haitianos no Brasil, construindo suas próprias táticas, em muitos casos contrapondo às dos haitianos.

Essa coletividade reflete no poder de territorialização da mobilidade haitiana no Brasil por, sobretudo três características: a capilaridade de suas relações socioespaciais, o caráter coletivo de sua mobilidade e o poder associativista dos lugares por onde os haitianos passam.

Nesse sentido, o presente artigo, a partir dessas características, analisa a ideia de território-rede, presente na análise geográfica e que entende as relações de poder e as potencialidades da formação de redes como a de imigrantes que produzem novas formas de ver e práticas políticas para imigrantes. Será estruturado da seguinte maneira: os encargos conceituais da ideia território-rede para a geografia e suas implicações a imigrantes no espaço, a discussão da capilaridade de grupos haitianos no Brasil na década de 2010 e o cruzamento da ideia território-rede e o poder dessa capilaridade.

\section{O BRASIL E O HAITI NO PANORAMA DA MIGRAÇÃO: CRUZAMENTOS POSSÍVEIS}

As políticas de imigração no Brasil começam a ser pensadas dentro de uma estrutura macro somente a partir da chegada da corte portuguesa no Brasil, em $1808^{1}$. É no século XIX que se intensifica a discussão do imigrante vinculado à força de trabalho, na qual podemos destacar três características que revelam a importância da criação de tais políticas: Primeiro, o esgotamento na escala mundial da força do trabalho escravo, gerada em alguma escala pela revolução negra no Haiti (que voltaremos mais adiante); segundo, as dificuldades enfrentadas pela ascensão do capitalismo mundial pelas potências europeias em absorver força de trabalho, gerando êxodo rural, precarizando mais ainda a situação da classe trabalhadora de base, principalmente em países como Itália e Alemanha, o que levou a duas consequências: acordos entre países colonizadores e escoamento da rede bancária de produção para países colonizados; e terceiro, a necessidade ideológica das oligarquias no Brasil em mudar o perfil do trabalhador brasileiro.

O reflexo dessa conjuntura são as políticas subvencionadas de imigração inscritas no percurso do século XIX. Dentre elas, a entrada dos principais fluxos migratórios entre alemães a partir de 1824, italianos em 1870 e japoneses entre 1890 e 1914 . O que elas 
marcam entre si são as contradições e incoerências de políticas migratórias sempre inscritas por interesses secundários ao migrante, relevantes por interesses cuja prioridade é a manutenção da desigualdade, a qualquer preço, na restrição dos fluxos migratórios e na formação de um constructo social baseados no preconceito e na hierarquização dos processos de mobilidade no Brasil ${ }^{2}$.

No decorrer do século XX há a intensificação desse processo com a legitimação das políticas restritivas pelo Estado Novo e a implementação do Conselho de Imigração e Colonização, no qual as ideias de cunho eugenistas foram o mote para uma série de intervenções na entrada tanto de imigrantes europeus mas, sobretudo de negros e outras raças que não a branca. A raça e o trabalho continuaram assim sendo, o motor para a implementação dessas políticas.

Se não houve uma pressão para mudanças sérias com a criação de organizações internacionais, bem como as intervenções mais diretas das alas progressistas religiosas em grande medida do catolicismo, não seria na ditadura militar brasileira (1964 - 1985) que se mudaria o cenário. O Estatuto do Estrangeiro - aprovado em 1980 e consolidado em 1981 - caracteriza um instrumento claro cujos interesses políticos promovem o discurso do migrante ideal. O final do século XX, marcado por novas mobilidades entra países latino-americanos, sobretudo colombianos, peruanos e bolivianos, além de congoleses e outras nacionalidades africanas, aponta as rusgas histórico-sociais que envolvem paulatinas decisões restritivas: dificuldades várias enfrentadas por imigrantes pobres em adquirir cidadania plena no Brasil.

Por outro lado, o Haiti tem uma história marcada por três principais características que levam ao atual processo maciço de emigração, sobretudo para os Estados Unidos: primeiro, a paulatina construção e consolidação das redes de violência, muitas vezes legitimada pelo Estado (francês, haitiano, americano), muito derivado de toda uma história de desigualdade pela violência do trabalho escravo e tráfico negreiro, no qual teve como resultado um país núcleo de insurgências culminando na Revolução Haitiana (reconhecida pela França em 1802); segundo, a concentração de serviços públicos e de base - como saúde e educação - bem como sua interação urbana determinadas na região oeste (onde se localiza a capital Port-au-Prince), o que fragilizou sua estrutura ainda mais no pós terremoto em janeiro de 2010 e terceiro, sua estrutura social marcada por extensas fragilidades, dentre elas a concentração de poder e riqueza entre uma elite militar historicamente definida.

Embora a revolução haitiana tivesse como preceito a igualdade, liberdade e fraternidade francesa, as respostas à busca pela liberdade negra foram mundialmente cruéis, sobretudo no chamado "medo negro", e na onda de possíveis insurgências por todo o mundo. C.R.L. James (2010) aponta várias perspectivas desse constructo de violência ainda no final do século XVIII e que propulsionou eventos de escamote amento da democracia, ainda no século XIX. O importante é considerar as três principais frentes de emigração no século XIX que colaboraram para um fluxo permanente de emigração até os dias de hoje, a mobilidade para a França, para os Estados Unidos e para a República Dominicana (os dois últimos são considerados, ainda hoje, os principais fluxos).

No século $\mathrm{XX}$, duas principais características são: Primeiro, o ciclo de dependência, fomentado pela instabilidade política que não foi apoiada em nada pelas comissões mundiais, culminando na colonização norte americana em 191.Em segundo o desconhecimento das idiossincrasias da população haitiana, desde a falta de interesse em ascender a sociedade com recursos básicos de educação e desenvolvimento social, o que gerou uma desigualdade social ímpar. Diferente do que ocorreu do outro lado da Ilha de Santo Domingo, na República Dominicana, no qual a fomentação da exploração canavieira subserviente às grandes potências, que impulsionou a emigração haitiana, e o 
que levou a políticas extremamente restritivas e a um exacerbado ódio entre dominicanos e haitianos.

Contudo, o Haiti - e a Ilha de Santo Domingo no geral - possui uma localização estratégica para os interesses mundiais, sobretudo norte-americanos. Em toda sua história política do século XX, os desafios da violência, somado à desigualdade e à sua inserção a lógica liberal foram presentes nesse percurso também geopolítico.

\section{GEOGRAFIA, MOBILIDADE E O TERRITÓRIO-REDE: PERSPECTIVAS CONCEITUAIS}

A problemática da rede na ciência geográfica, em paráfrase a Souza (2013) tornou-se "coqueluche" no Brasil meados da década de 1990, embora tenha sido alavancado por geógrafos franceses, americanos, entre outros, uma década antes. É notório em sua apreensão que o estudo das redes na geografia segue dois caminhos: um, o estudo dos pontos de relação entre um ou mais espaços, de âmbito mais material, prático; e dois o estudo das redes que interligam e produzem contiguidades espaciais, sobretudo o exemplo das redes de ativismo social, que mobilizam espaços e transformam o poder de decisão e de mutação desses espaços.

O sentido mais pragmático da rede constitui a análise das políticas e das transformações nas escalas da categoria do pensamento geográfico - rede urbana, rede regional, entre outras - e apreende o poder de comando e decisão dessas redes em optar por transformações no espaço que garantem a primazia de um determinado grupo social.

Essa segunda apreensão, das contiguidades é cara, pois as redes socioespaciais promovem o vaivém constante das políticas espaciais, regionais e territoriais conforme a emergência da mobilização social.

O fato é que, se, além da própria rede urbana, também as redes viárias, e particularmente as ferroviárias, estiveram na pauta dos geógrafos desde cedo, atualmente os geógrafos e outros profissionais vinculados à pesquisa socioespacial já iniciaram a exploração do conceito a partir de numerosas e muito variegadas perspectivas. Uma trincheira particularmente interessante de aplicação do conceito de rede, pelas ciências da sociedade, é aquela que busca capturar aspectos fundamentais da dinâmica e do modo de estruturação de protestos e ativismos sociais com o auxílio desse conceito (SOUZA, 2013, p. 168)

Nessa perspectiva, é salutar também a contribuição de Haesbaert no entendimento e na sistematização do estudo das redes na geografia e na problemática do território-rede.

Para tal, há um problema na análise das redes que aponta para a dualização entre território e rede, e que dificulta a apreensão de um conceito que está imbricado por si só. Para ele, redes constituem territórios e vice-versa. Esse dualismo na geografia, sobretudo na relação euclidiana ou não euclidiana, escamoteia uma realidade no qual torna explícito que a sociedade em rede não implica no fim de territórios, mas na formação de novas territorialidades.

Vale ressaltar que para a geografia território, em resumo, significa toda atuação no espaço que forma relações de poder. Nesse sentido também, Haesbaert em $O$ mito da desterritorialização aponta que o discurso de fim de territórios não existe, e que o engendramento de relações de poder no espaço não se finda com a globalização, muito pelo contrário, as relações tornam-se cada vez mais balizadas pelas relaçõos de poder, e, portanto, instituídas de territórios. No tocante aos territórios-rede:

Identificamos três grandes perspectivas teóricas na relação entre território e rede: uma que subordina a rede ao território (como em muitas leituras da 
geografia mais tradicional), outra que, dicotomicamente, separa claramente território e rede (como na abordagem de Bertrand Badie), e, finalmente, uma terceira, que trabalha com o binômio território-rede, historicamente relativizado, a rede atuando ora como feitos territorializadores, ora com efeitos desterritorializadores [...] as redes podem assim estar a serviço tanto de processos sociais que estruturam quanto de processos que desestruturam territórios. Mas a dinâmica do elemento rede tornou-se tão importante no mundo "pós-moderno" que não parece equivocado afirmar que a própria rede pode tornar-se um território (HAESBAERT, 2009, p. 298).

Assim, os territórios-rede são vias de movimento e circulação de espacialidades diversas, cujo movimento e diversidade são os atrativos. Vale ressaltar que a perspectiva de rede, ou de territórios-rede, embora complementar difere da análise metodológica aplicada às redes de sociais de imigração, que possibilita visualizar o migrante numa gama de relações (dentre elas, a comunicação, os cenários políticos, as interfaces sociais), e admite a análise relacional em plenitude.

Essas redes sociais implicam um processo de articulação entre sociedade e ação, isto é, do momento da decisão de migrar, seus sentidos e suas perspectivas sociais e subjetivas de quem migra, e que constituem socialmente relações de vida, e mobilizam não só o sentido de migrante no lugar que chega, como suas relações interpessoais, sua condição de sujeito e de grupo coletivo, suas articulações de sobrevivência e de escolhas.

As redes sociais de migração refletem que espaço de hoje poderá ser o lugar de amanhã, assim como um território e vice-versa. É, portanto uma categoria de análise dos estudos migratórios, no que território-rede é outra categoria de análise que também pode ser utilizada.

No tocante à mobilidade, Haesbaert enfatiza dois cenários importantes na constituição de territórios-rede a partir da migração. O primeiro é da potencialização de construir novas relações que não sejam as instituídas pelo poder hegemônico, como o Estado e as grandes empresas, que são hoje as que mais funcionalizam espaços de poder versus espaços subordinados, no qual tais territórios-rede possuiriam a capacidade de promover o conflito às contradições socioespaciais. Mas também promovem novos territórios-rede e novas relações de poder, como as relações entre facções do tráfico nas favelas do Rio de Janeiro ou das organizações extremistas no Oriente Médio, por exemplo.

O segundo cenário é que esses territórios-rede enfatizam espaços donde a migração e a marginalização tangenciam, e onde as possibilidades de transformação socioespaciais tornam-se paulatinamente escassas, que é o caso dos aglomerados de exclusão. Conforme ele aponta:

\footnotetext{
Os aglomerados de exclusão, mais do que espaços à parte, claramente identificáveis, são fruto de uma condição social extremamente precarizada, onde a construção de territórios "sob controle" (termo redundante) ou "autônomos" se torna muito difícil, ou completamente subordinada a interesses alheios à população que ali se reproduz [...] No caso dos aglomerados, maior mobilidade não está ligada à manutenção da segurança, ao controle e mesmo à opção diante dos circuitos de deslocamento, como no caso da elite de grandes executivos (...) mas à falta de opção, à insegurança (principalmente frente ao emprego) e à perda de controle sobre seus espaços de vida (HAESBAERT, 2009, p. 327).
}

Nessa perspectiva, os aglomerados de exclusão representam maior parte das situações em que o imigrante hoje, no mundo globalizado, se insere. Privado da 
construção de territórios e principalmente territorialidades amiúde a insegurança e a subordinação de seu próprio poder de decisão e de sua escolha.

\section{A CAPILARIDADE HAITIANA NO BRASIL}

Por um lado, temos as idiossincrasias do processo diáspora donde emigração e imigração fazem parte da mesma sessão de estratégias, ora da população haitiana, que conforme Handerson articula a mobilidade como estratégia de ascensão econômica e social. Por outro lado, temos a articulação de uma rede de espacialidades que constituem uma estratégia migratória por vezes até peculiar no caso dos haitianos. Isso se dá pela profunda capilaridade demonstrada histórica e espacialmente do ser haitiano diáspora, vide mapa a seguir:

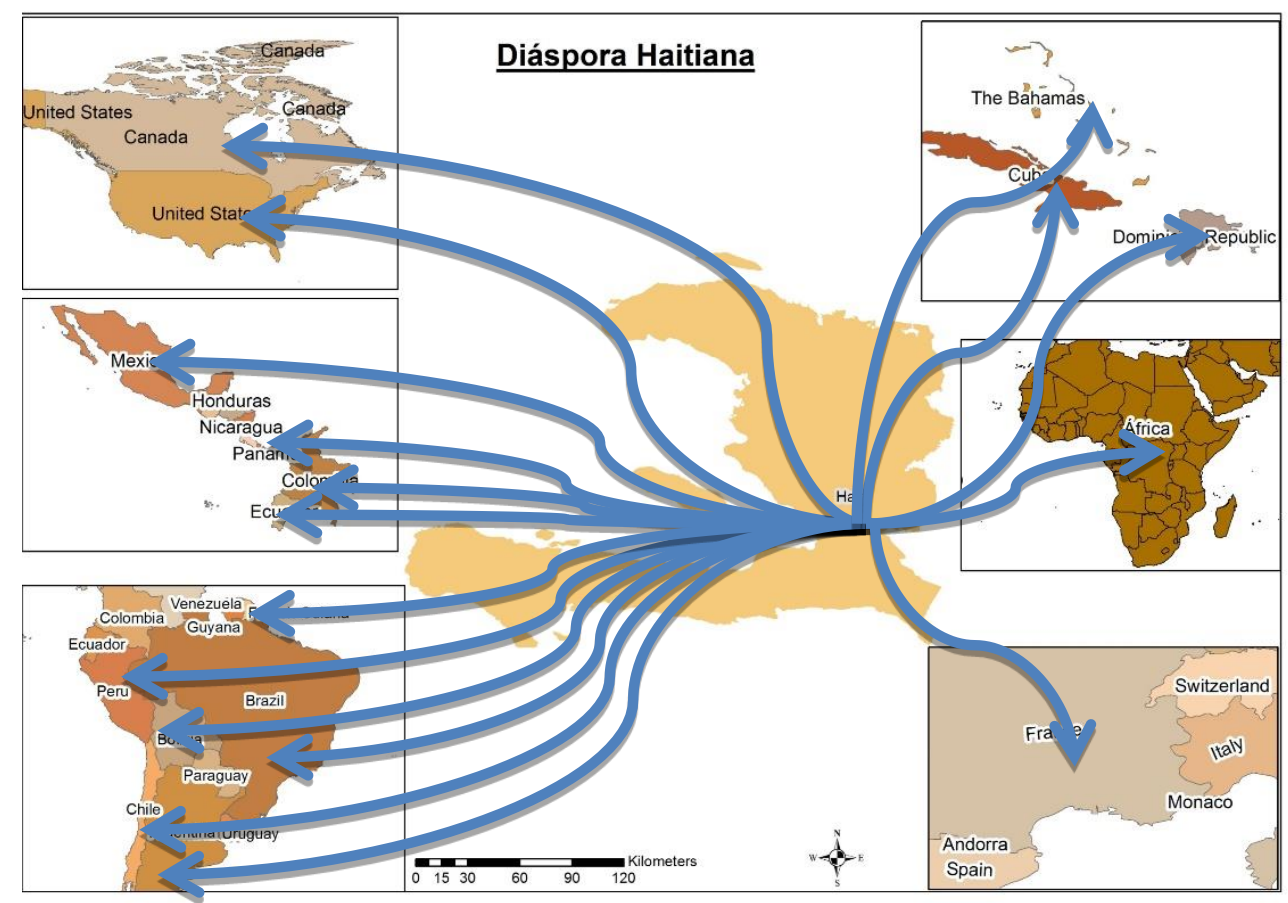

FONTE: HANDERSON (2015). Elaboração própria.

Decorre da imagem uma reflexão de ordem geopolítica, quanto às influências de países assentados pela ideia de soberania moderna foram importantes para o senso do sujeito diáspora ratificados por Handerson (2015), cujas mobilidades tendem a percorrer tais influências e outras além (França, Estados Unidos, República Dominicana, Cuba, Bahamas e África dentre outros) e uma reflexão de ordem socioespacial, quanto à construção de redes e zonas políticas de apoio, espraiamento e novas estratégias diásporas.

Tal fluxo é consolidado em primeiro lugar a partir da intensificação das redes de violência seja nas comunas rurais ou no raio da capital Porto Príncipe, seja na profunda desigualdade espacial promovida entre a capital e as demais localidades do país. Junto a isso, as políticas de intensificação da violência legitimada de Papa Doc e baby Doc, bem como a ditadura de Cedrás, já no final do século XX contribuíram para a formação de milícias que até hoje rescindem no Haiti e inclusive interferem no processo democrático ${ }^{3}$.

Em segundo lugar, a capilaridade migratória de imigrantes haitianos participa de uma conjuntura da política do medo de países atuantes politicamente no Haiti, como Estados Unidos, República Dominicana, França dentre outros que promovem uma série de entraves no sentido de conter a mobilidade para tais países. 
No tocante à capilaridade da migração de haitianos via América do Sul, tomemos dois elementos importantes para situar não só as potencialidades, mas as relações de poder contidas no processo, seja dos grupos migrantes, mas sobretudo dos agentes pelos quais esses migrantes passam.

O primeiro elemento refere-se ao que denominou essa política do medo. Tal política tem pelo menos duas escalas importantes: uma, a escala do migrante haitiano e o medo do fracasso no trânsito ao lugar chegado. Ele se reflete na multiplicação das trajetórias e das possibilidades de fluxos entre Américas; e duas, a escala dos países cuja importância política é intrínseca à migração, como no caso de Estados Unidos e França no sentido da primazia política e econômica para o Haiti, e República Dominicana no sentido da articulação política, social e geográfica como país vizinho. Tanto EUA e França quanto República Dominicana arrefece meados da década de 2010 - e no transcurso da década, como agora em 2017/2018 - a entrada de haitianos em seus territórios. Fica claro no relato de Handerson (2015), ao trajeto de um de seus entrevistados em uma cidade do norte do Haiti:

\begin{abstract}
Quando James chegara a Grand Turck, decepcionara-se com a infraestrutura, melhor dizer, a falta dela, comparando com a República Dominicana onde residira. Segundo ele, a Ilha "era no meio do mato" (nan rak bwa), as construções de madeira e precárias. $\mathrm{O}$ fato de ser um lugar pequeno $\left(18 \mathrm{~km}^{2}\right)$ nos termos dele, "era possível passar de uma ponta da Ilha a outra em dez minutos", já logo queria deixar o local. Somando-se a isso os dias passando sem trabalho ou dinheiro e o medo de serem deportados pelos policiais, eles evitavam circular nas ruas de Grand Turck. Nessa época, os policiais ingressavam nas casas para procurar pessoas em situações indocumentadas para deportá-las e, ao mesmo tempo, multavam o proprietário da casa onde elas se abrigavam. Por conta disso, James ficara uma semana dormindo no carro do amigo (HANDERSON, 2015, p.207).
\end{abstract}

Essa política do medo, no qual é possível visualizar em todo o histórico de processos emigratórios do Haiti resulta de um projeto maior de construção de barreiras à migração de oriundos de países pobres/e ou em conflito e /ou discordantes a lógica global financeira (Sassen: 1991,1996, 2016; Harvey: 2003; Brown: 2011, entre outros), que acentuam as desigualdades e intensificam a relação de poder no qual esses países possuem em relação ao mundo. É um jogo de cartas bem marcadas.

$\mathrm{O}$ segundo elemento refere-se aos trâmites à rota sul-americana. Podemos apontar os acordos multilaterais entre o Mercado Comum do Sul - Mercosul - e Américas (Acordo do México e Acordo Mercosul) como impulsionadores a entrada de novos migrantes, aprofundados no primeiro capítulo. Eles tonalizaram as possibilidades de passagem para países como Equador, Colômbia, Peru e Bolívia. Essa política vinculada à diplomacia solidária consolidada na gestão do governo Lula no Brasil e às resignificâncias dos percursos migratórios devido ao arrefecimento das fronteiras no mundo possibilitou novas referências para rotas migratórias. Não que as atitudes diplomáticas da América do Sul acolheram a aportaram imigrantes em toda a sua conjuntura, pelo contrário. Como veremos adiante, as estratégias de mobilidade do Estado podem ser o revés das dos migrantes. Nesse sentido:

No caso dos haitianos, há um duplo nível: 1) os agentes estatais brasileiros, peruanos, equatorianos, franceses e surinameses constituíram mecanismos e dispositivos de barreiras para controlar a chegada de novos migrantes; 2) os haitianos desenvolviam novas estratégias, criando novos circuitos e rotas migratórias para alcançar os lugares, constituindo novos territórios da mobilidade (Faret, 2003). O conjunto dos lugares constitutivos de um território 
da mobilidade não são pontos isolados, eles se interligam através dos circuitos e das redes de mobilidade (HANDERSON, 2015, p. 181).

Tal capilaridade, conforme apontado possui várias justificativas, e em muitos casos a estratégia de migrar para o Brasil conflita com as ações políticas adversas a dos próprios migrantes. Não existe inimigo ou dualismo nesse processo, é um constructo político.

Essa capilaridade fica perceptível no mapa abaixo, pelas cores de cada rota de haitianos na década de 2010 no Brasil e na América Latina.

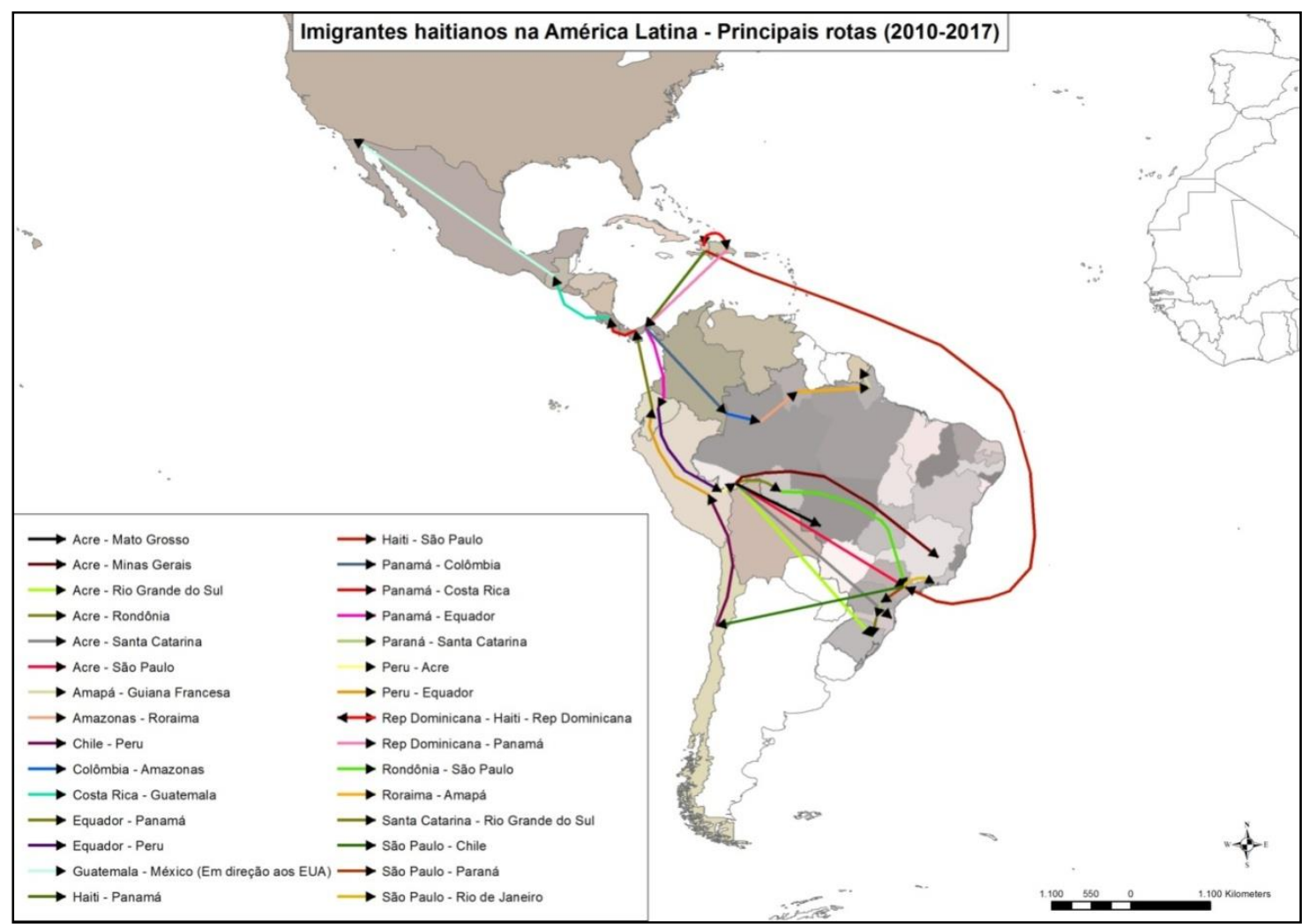

FONTE: NIEM e pesquisa de Campo. Elaboração própria.

Se por um lado empreende-se que essas estratégias não passam de arranjos em que o imigrante não participa plenamente de suas escolhas, ou que é uma estratégia funcional, a fim de participar do melhor mercado de trabalho, é exatamente pelo constructo subjetivo e coletivo dos migrantes haitianos em mover-se e mobilizar suas táticas de sobrevivência que a escolha política ressalta da possível falta de plenitude delas. Parece mais claramente que o discurso do trabalho é uma reprodução da necessidade do Estado em legitimar suas estratégias conflitantes com as dos migrantes do que a relevância maior à mobilidade. $\mathrm{Na}$ realidade, é o que oferece o trabalho - recursos, garantia de sustento e sobrevivência - o que realmente o migrante almeja.

Nesse sentido, a globalização transforma - e progride - as relações do capitalismo para acirrar ainda mais as diferenças e os conflitos, voltados a interesses que buscam ainda a tomada de porções de territórios a fim de mais capital. Novos dispositivos para velhas estratégias. Indefinir as barreiras de restrição, portanto, só se torna presente para as grandes corporações atrás de promoção invariavelmente de capital. Restringir e acirrar ainda mais a construção de muros em fronteiras, frontiers, borders entre outros, é a afinação conveniente a essa liberdade induzida. 


\section{HAITIANOS NO BRASIL: REDES DE MOBILIDADE OU AGLOMERADOS DE EXCLUSÃO?}

O caso do Brasil é peculiar quanto às políticas de mobilidade. Embora haja um consenso discursivo de abertura das portas para estrangeiros, os atravessamentos são contraditórios. No caso dos haitianos no Brasil, por exemplo, da entrada pela fronteira boliviana e peruana, a entrada pelo Sudeste e Sul até suas condições de permanência no país é marcado por um longo e cansativo processo de inserção, tanto para com a sociedade local quanto aos dispositivos políticos que ora o constituem no lugar chegado, mas ratifica diferenças e forma lócus de diferenças propositais. Um exemplo é sua condição entre o legal e o ilegal, e a garantia de sobrevivência no lugar em que se instala, onde na maioria das vezes, e por várias razões, vão para as periferias. Também, a falta de diálogo recorrente com o poder local em garantir o acesso à "cidadania" em amplo sentido. Da mesma maneira que os muros físicos, as fronteiras da política que apartam e ratificam a segregação e o discurso de "invasão" são partes desse processo apresentado.

Afinal, a imigração haitiana no Brasil reflete a potencialidade da formação de novas redes e ao questionamento ao instituído que diverge com a realidade socioespacial dos migrantes ou ela se enquadra na formação de aglomerados de exclusão?

Vale ressaltar que os aglomerados de exclusão não são fixos, eles são temporários e podem ser transformados em novas redes e ter novas territorialidades. Mas ainda parece um pouco nebuloso, ao analisarmos mais a fundo um fluxo como a de haitianos, profundamente marcado pela capilaridade desde o início, até que ponto eles contemplam sua espacialização de maneira subordinada ou até que ponto a capilaridade deixa de potencializar politicamente o papel de suas escolhas em sair do Haiti.

A reflexão das relações de poder imbricadas nos espaços formando novos territórios possui também o caráter dinamizador de novas territorialidades construídas nestes que muitas vezes divergem dessas relações de poder. Parece, portanto, que a mobilidade haitiana no Brasil anunciou uma série de transformações na política brasileira, tirou da zona de conforto uma série de debates e perspectivas no qual o instituído era o resoluto, e propiciou novas fontes de relação entre imigrantes, em várias escalas.

Contudo eles continuam vítimas de uma série de ações, sejam discursos racistas, ou superexploração escusa - muitos alegam que visivelmente trabalham mais que funcionários locais em fábricas ou empresas no qual empregam imigrantes, ainda que com os mesmos direitos e ganhando o mesmo salário - ou movimentam um mercado imobiliário alternativo das periferias pela falta de documentos exigidos em um aluguel regularizado - como é o caso de boa parte dos haitianos que vivem na serra sul-riograndense.

Entende-se que essa apreensão da constituição de territórios-rede por haitianos no Brasil não é e nem deve ser maniqueísta, e talvez esse seja o caráter nebuloso da ideia de aglomerados de exclusão. É do próprio vaivém característico do migrante, inclusive na forma de compreender e agir no espaço. Da mesma maneira em que é subordinado a determinadas decisões, as atitudes e os conflitos são postos e são cotidianamente convertidos em luta socioespacial.

A corrupção, a violência e a dependência são as três marcas profundas no Haiti, e são as marcas que romperam outras fissuras com o agravamento de caráter geomorfológico - o terremoto é uma ponte para tal - donde qualquer problema de ordem ambiental se torna mais grave se unido a problemas muito mais abrangentes de natureza política e socioeconômica. Por isso também que definir o terremoto como um dos motivos para a intensificação da saída de haitianos torna-se correto, mas se não visualizarmos o conjunto de fatores no qual o terremoto é a ponta, o caráter das estratégias de mobilidade 
$\overline{\text { aliado aos agenciamentos da imigração torna-se fragmentos de um enredo muito bem }}$ amarrado.

Não à toa as múltiplas táticas para imigrar, costurando a cada impossibilidade de realizar o traço diáspora novas rotas, novos trânsitos e perspectivas. Não à toa também a resignação em atravessar as adversidades e as relações exploratórias dos trajetos perpetrados, a fim de evitar confusão, como muitos dos haitianos em que conversei apontaram. Por fim, da diversidade de formas de expressão no qual eles conseguiram se posicionar no Brasil, principalmente nas associações de imigrantes espalhadas pelo país.

Entendemos que estratégias de mobilidade não são divergentes ou contraditórias. Isto quer dizer que tais estratégias participam de uma coetaneidade, elas convivem no tocante ao fazer migrante e ao ser migrante. Nesse sentido, na permanência coexiste a mobilidade e vice-versa.

Essa coexistência fica clara na mobilidade haitiana para o Brasil, quando os agenciamentos perpetrados pelos imigrantes vêm e voltam conforme a emergência de suas próprias necessidades. Em trabalhos de campo no Acre, Rio Grande do Sul e São Paulo, nas conversas com os imigrantes foi possível perceber um conhecimento dimensionado do Brasil e suas principais características quanto a ofertas de trabalho e condições de melhoria de vida, muito pelos emaranhados de redes existentes a partir de outros grupos chegados anteriormente.

Sobretudo é válido refletirmos sobre os desencontros entre o discurso do Estado, que em grande medida vincula a relação trabalho, das intenções de trabalho dos migrantes haitianos. Toda construção e sensibilidade em pesquisas que apontam o fluxo de haitianos no Brasil aportam a questão trabalho como preponderante. Nos parece, contudo, que o salutar é o trabalho para a melhoria das condições de vida de um grupo, de uma família e dos próprios migrantes que chegam ao Brasil.

\section{À GUISA DE CONCLUSÃO...}

Na imigração de haitianos para o Brasil, não somente a busca e a tentativa da ação diáspora são apontadas, como - e principalmente - os mecanismos que essa prática de ser diáspora são espraiadas conforme estratégias de um grupo, de um apoio de toda uma família, e ainda que novas redes de antigos desconhecidos que se encontram vão surgindo, as famílias, no seu sentido mais amplo vão se comunicando, se articulando a partir da migração. Esse sentido diásporo e parte dessa ação que era um desacordo de suas próprias articulações políticas entre grupos minoritários urbanos e ricos tornam-se uma ação, um verbo a partir do migrar de grupos pobres, das zonas rurais.

Mas as geometrias de poder acontecem. O desacordo das políticas de migração e das heranças sociais que produzem e reproduzem estigmas para com a migração e o migrante, aliadas ao conceito de um Brasil dotado de inúmeras possibilidades e escolhas, representatividades construídas ainda no Haiti. A configuração do país para se tornar uma grande nação em desenvolvimento equiparado aos grandes estados nacionais. Para tanto, copiou a mesma fórmula apontada pelos seus colonizadores.

A entrada recente de imigrantes no Brasil, tal o caso dos haitianos, mas também senegaleses, ganeses, angolanos, sírios, dominicanos, equatorianos, colombianos, peruanos, bolivianos, e muitos outros possuem múltiplas facetas que questionam essas dualidades da política e da constituição social que traz como reflexo dessas políticas. Não só pelo fato do país estar em um contexto no qual faz jus anos de tentativa de progressão ao seu crescimento - o que acarreta, tal como em países chamados desenvolvimentistas - na entrada de imigrantes pobres à procura de qualidade de vida, mas também porque suas relações não foram e nunca serão duais. 
Isso implica dizer que a compreensão da imigração haitiana para o Brasil envolve uma multiplicidade de agenciamentos, uma pluralidade de eventos cujo trabalho é um elemento, e não o meio e o fim para chegar ao processo desencadeador da emigração haitiana. Daí as estratégias de permanência e de mobilidade possibilitarem a compreensão dessa multiplicidade, na mobilidade enquanto tática política de mudança, desencadeada por fatores tão plurais quanto a própria mobilidade.

Da mesma maneira, a capilaridade envolvendo processos socioespaciais reformulam práticas espaciais, e promovem novas territorialidade para com imigrantes haitianos bem como aos brasileiros. Embora a escala dos acontecimentos permeie uma série de implicações e problemas, não tornar um imigrante um problema que vai construir políticas que englobem, de fato, as perspectivas, as territorialidades e as práticas espaciais desses imigrantes o caminho real e efetivo.

A capilaridade dos haitianos, bem como as transformações políticas imbricadas nessa capilaridade pode ser considerada territórios-rede, assim como suas práticas políticas de caráter associativo, na formação de uma política de base para assistência e acolhimento a chegada e permanência de imigrantes haitianos no Brasil. Da mesma maneira, o preconceito, a subordinação dentre outros processos no qual o espaço se restringe, bem como suas práticas socioespaciais ingeridas muitas vezes alheiamente por esses imigrantes precisam ser repensadas também enquanto políticas de acesso pleno à cidadania.

\section{NOTAS}

1 - Tal como estrutura macro política de interesse do Estado no trabalho assalariado. Vale ressaltar o tráfico negreiro e a presença do imigrante europeu desde o século XV.

2 - Para maiores informações sobre o assunto, Seyferth (1999; 2002; 2014), Koiffman (2012), dentre outros apontam o caráter restritivo e secundário quando se trata do interesse de imigrantes no Brasil no século XIX, e principalmente no século XX, com a ratificação da política de branqueamento brasileiro.

3 - Temos como exemplo notícia de final de 2016, onde ocorreu a última eleição no Haiti, em volta a uma série de conflitos entre milícias locais controlando as principais favelas de Porto Príncipe até o caráter duvidoso do resultado da maior parte das eleições haitianas neste século: "La tension est montée au cours des vingt-quatre dernières heures dans l'attente des résultats. Des tirs d'armes automatiques ont résonné tôt, lundi matin, dans les quartiers populaires de Belair, de Solino et de Delmas, à Port-au-Prince, la capitale. Une barricade de pneus enflammés a interrompu la circulation sur une artère fréquentée [...]Venus des quartiers les plus -pauvres de Port-au-Prince, des partisans de Maryse Narcisse ont manifesté en début de semaine, dénonçant « un coup d'Etat électoral » en préparation. Rudy Hérivaux, le porte-parole du PHTK, le parti fondé par l'ancien président Michel Martelly, avait proclamé la victoire de Jovenel Moïse, violant la règle interdisant aux partis d'annoncer des résultats avant le CEP." Disponível em : http://www.lemonde.fr/ameriques/article/2016/11/29/jovenel-moise-petit-paysan-qui-reussit-nouveaupresident-haitien 5040106 3222.html.

\section{REFERÊNCIAS BIBLIOGRÁFICAS}

BROWN, Wendy. Walled states, waning sovereignty. Nova York: Zone Books, 2011. HAESBAERT, Rogério. O mito da desterritorialização: do "fim dos territórios" à multiterritorial idade. $3^{\text {a }}$ Ed. Rio de Janeiro: Bertrand Brasil, 2009.

HANDERSON, Joseph. Diaspora. As dinâmicas da mobilidade haitiana no Brasil, no Suriname e na Guiana Francesa. - Tese. 2015. Rio de Janeiro: UFRJ/Museu Nacional, 2015. 
HARVEY, David. O novo imperialismo. São Paulo. Edições Loyola, 2003.

JAMES, C. L. R. Os Jacobinos negros: Touissant L' Ouverture e a Revolução de São Domingos. São Paulo: Boitempo, 2010.

KOIFMAN, Fábio. Imigrante ideal: O Ministério da Justiça e a entrada de estrangeiros no Brasil (1941-1945). Rio de Janeiro: Civilização Brasileira, 2012.

MASSEY, Douglas. et. al. Return to Aztlan:the social process of international migration from western Mexico. Los Angeles: University of California, 1987.

SAYAD, Abdelmalek. O migrante e os paradoxos da alteridade. São Paulo: EDUSP, 1998

SEYFERTH, Giralda ... [et al.]. Mundos em movimento: Ensaio sobre migrações. Santa Maria: Ed. UFSM, 2007.

Imigração e (re) construção de identidades étnicas. Cruzando fronteiras

disciplinares. PÓVOA NETO, Hélion; FERREIRA, Ademir Pacelli (Org.). Rio de Janeiro: REVAN, 2005.

. Imigração e a questão racial no Brasil. REVISTA USP, São Paulo, n.53, p. 117 149, março/maio 2002.

O Estado brasileiro e a imigração. Caminhos da migração. SANTOS, Miriam de Oliveira; PETRUS, Regina; PÓVOA NETO, Helion; GOMES, Charles (Org.). Rio de Janeiro. Léo Christiano Editorial, 2014.

Os imigrantes e a campanha de nacionalização do Estado Novo. In.: REPENSANDO o Estado Novo. PANDOLFI, Dulce (Org.). Rio de Janeiro: Ed. Fundação Getulio Vargas, 1999.

SASSEN, Saskia. Expulsions: brutality and complexity in the global economy. Cambridge: Harvard University Press, 2016.

Losing control? Sovereignty in an age of globalization. New York: Columbia University Press, 1996.

Press, 1991.

The Global City: New York, London, Tokyo. Princeton: Princeton University

SOUZA, Marcelo Lopes de Os conceitos fundamentais da pesquisa sócio-espacial. Rio de Janeiro: Bertrand Brasil, 2013.

VALLER FILHO, Wladimir. O Brasil e a crise haitiana: a cooperação técnica como instrumento de solidariedade e de ação diplomática / Wladimir Valler Filho. - Brasília: FUNAG, 2007. 